\title{
Escribir sobre la primera infancia. Las prácticas biográficas de las profesionales
}

\section{Resumen}

Desde pricipios del siglo XX, forma parte de las prácticas comunes de numerosas familias el conservar la huella de las «primeras veces» por la imagen o el escrito. Estas huellas materiales sobre el nacimiento y la primera infancia, lo mismo que las prácticas asociadas, participan del movimiento que acompaña, tanto como testimonia, la figura del padre biógrafo y el proceso biográfico en el seno de la familia (Francis, 2006, 2011, 2012). Trata el estudio de un cuerpo constituído de objetos tales como los cuadernos de vida, libretas de vida o sea «cajas de tesoro» y entrevistas con profesionales que los realizan: maestras en escuela de párvulos, educadoras, auxiliares familiares y maternas. Dan los resultados una idea de las prácticas biográficas de las profesionales y de los sentidos que encierran. Cuando el nacimiento, la primera infancia y la niñez, se va tejiendo una trama de narraciones en la que unos objetos, "saturados de significados implícitos» (Kaufmann, 1997, p. 113) contribuyen a la producción de relatos sobre el chiquillo, sobre su historia individual o sobre su historia dentro o por el grupo, el de la familia de acogida, de la guardería infantil, de la escuela de párvulos. Así pues, suelen estos cuadernos y libretas de vida testimoniar de la perspectiva biográfica (delory-Momberger, 2005) y de los espacios de relación consigomismo y con otros - profesionales, padres, el niño mismo (co)productor de sus huellas, que encierra. Estos relatos que rayan en unos escritos «del yo» y "para el prójimo» (Lejeune \& Bogaert, 2006) están entre litteracy y memoracy ya que ahí también se encuentran transformados « la relación y la función de la memoria, de la huella y del archivo» (Gardey, 2008).

Palabras-clave: Huellas biográficas; Profesionales; Primera infancia.

\author{
Nathalie Chapon \\ Doutora em Ciências da \\ Educação pela Universidade Aix- \\ Marseille - França \\ nathalie.chapon- \\ crouzet@univ.provence.fr

\section{Véronique Francis} \\ Doutora em Educação pela \\ Universidade de Orléans - França \\ veronique.francis@wanadoo.fr
}

\footnotetext{
Para citar este artigo:

CHAPON, Nathalie; FRANCIS, Véronique. Escribir sobre la primera infancia. Las prácticas biográficas de las profesionales. Revista Linhas. Florianópolis, v. 16, n. 32, p. 93-110, set./dez. 2015.
} 


\section{Writing about early childhood. Biographical Practices of Professionals}

\begin{abstract}
Since the early twentieth century, it is part of the common practices of numerous families to keep a record of the "first times" by means of image or writing. These material records about the birth and early childhood, as well as the associated practices, take part in the movement that accompanies, as witness, the person of the father biographer and the biographical process within the family (Francis, 2006, 2011, 2012). This study consists of a body of objects such as books of life, diaries, that's to say "treasure boxes" and interviews with professionals who make them: preschool teachers, educators, family and mother helpers. The results give an idea of biographical practices of professionals and the meanings that they contain. At birth, infancy and childhood, a web of narratives is woven in which some objects, "full of implicit meanings" (Kaufmann, 1997, p. 113), contribute to the production of reports on the child, about their individual history or their history within the group, the welcoming family, daycare, preschool. Thus, these notebooks of daily life usually testify about the biographical perspective (DeloryMomberger, 2005) and about the spaces of relationships with themselves and with others - professionals, parents, the child himself (co)producer of their records. These reports appearing in some writings of "the self" and "to the neighbor" (Lejeune \& Bogaert, 2006) are among litteracy and memoracy, since here "relation and the function of memory, record and file" are transformed (Gardey, 2008).
\end{abstract}

Keywords: Biographical records; Professionals; Early childhood.

\section{Escrever sobre a primeira infância. As práticas biográficas das profissionais}

\section{Resumo}

Desde princípios do século XX, forma parte das práticas comuns de numerosas famílias conservar o registro das "primeiras vezes" pela imagem ou pelo escrito. Esses registros materiais sobre o nascimento e a primeira infância, assim como as práticas associadas, participam do movimento que acompanha, como testemunha, a figura do pai biógrafo e o processo biográfico no seio da família (Francis, 2006, 2011, 2012). Trata o estudo de um corpo constituído de objetos tais como os cadernos de vida, diários, ou seja, "caixas de tesouro" e entrevistas com profissionais que os realizam: professoras de pré-escola, educadoras, auxiliares da família e da mãe. Os resultados dão uma ideia das práticas biográficas das profissionais e dos sentidos que encerram. Quando do nascimento, da primeira infância e da meninice, vai-se tecendo uma trama de narrações na qual alguns objetos, "saturados de significados implícitos" (Kaufmann, 1997, p. 113), contribuem para a produção de relatos sobre a criança, sobre a sua história individual ou sobre a sua história dentro ou pelo grupo, da família que acolhe, da creche, da pré-escola. Assim, esses cadernos de vida e diários costumam testemunhar sobre a perspectiva biográfica (Delory-Momberger, 2005) e sobre os espaços de relação consigo mesmo e com os outros - profissionais, pais, a própria criança (co)produtor de seus registros. Esses relatos que aparecem em alguns escritos "do eu" e "para o próximo" (Lejeune \& Bogaert, 2006) estão entre litteracy e memoracy, já que se encontram transformadas aí "a relação e a função da memória, do registro e do arquivo" (Gardey, 2008).

Palavras-chave: Registros biográficos; Profissionais; Primeira infância. 
Se han desarrollado los enfoques biográficos en educación familiar y han ganado en visibilidad (Francis, 2012) a raíz de los estudios sobre las historias familiares (Sità, 2005), las prácticas biográficas paternas (Catarsi, 2008).

Desde principios del siglo XX, forma parte de las prácticas comunes de numerosas familias el conservar la huella de las «primeras veces» por la imagen o el escrito. Suelen realizarse cuando el nacimiento los «fragmentos biográficos» del diario de nacimiento o textos más largos, apareciendo o no al lado de la fotografía. Al rayar en los «escrito del yo» y «los escritos para el prójimo» (Simonet-Tenant, 2004; Lejeune y Bogaert, 2006), se destinan primero al niño pero también a menudo concierne a unos familiares.

Aparecida en los tiempos modernos en el seno del espacio familiar, esta producción biográfica del período de la primera infancia también se ha integrado en las prácticas profesionales. Si primero se trataba de iniciativas individuales, ahora las fomentan las instituciones. Se suelen preconizar de modo firme y sútil en el seno de instituciones tales como guarderías infantiles, escuelas de párvulos y las del campo de la protección de la infancia. El objetivo de la comunicación es sacar a luz estas prácticas biográficas en el período de la primera infancia en el contexto francés interesándose en las prácticas de las profesionales con cuadernos, libretas y álbumes «de vida». ¿Cómo se constituyen estos objetos y cuáles son sus formas? ¿Qué sentidos tienen para las profesionales? Son sometidas estas cuestiones al análisis a partir del material recogido en varios estudios cualitativos realizados entre 2008 y 2013 cerca de profesionales de la primera infancia de varios sectores.

\section{1 - Escrituras biográficas en el período de la infancia Las prácticas de la memoria en el seno de la familia}

Como lo demuestran los estudios sobre los escritos del fuero privado (Foisil, 1999), ya en los albores de la modernidad, testimonian prácticas de la memoria en el seno de la familia los libros de juicio, libros de familias, diarios, correos, memorias y autobiografía. Primero en las familias con patrimonio suelen los padres constituir «una memoria biológica y económica de la familia» (Cicchetti y Mordenti, 1984, citados por Cazalé Bérard 
y Klapisch-Zuber, 2004, p.808) apoyándose a veces en un esquema redaccional preciso, como en los libros de familias italianos. Se va desarrollando el relato de la experiencia y a continuación se expresa con varias formas. En efecto se fomentan los diarios personales para acompañar la educación de los jóvenes (Delieuvin, 2003; Hess, 1998; Illiade, 2006), especialmente el de las chicas (Lejeune, 1993). El escribir sobre sí se presenta como un ejercicio saludable, fuente de reflexividad. Soporte de educación, el escribir sobre sí también es soporte de memoria, tanto para su autor como para las otras personas que concierne. Acompaña al mismo tiempo que testimonia las experiencias asociadas a las rupturas biográficas, entre las cuales el nacimiento y la separación, en relación con la escolarización, el matrimonio, la muerte.

A partir del siglo XXI, se da una impulsión sin precedentes a los escritos familiares y se va desarrollando en todos los medios sociales en el momento del nacimiento y de la primera infancia. A raíz de la difusión de documentos incluyendo escritos recuadrados, dicho de otra manera, escritos a la vez explicativos y apoyados por un escrito preexistente que completar. Entre estos documentos, los primeros son las libretas de control sanitario, hechos para recetar, controlar y racionalizar las curas de los niños. En un primer tiempo destinadas a vigilar a los niños que se crian fuera o que dependen de la beneficiencia pública (Rollet-Echalier, 1990), estas libretas van a originar la libreta de salud, entregada por la maternidad al nacer el nene, a partir de los años 60 (sesenta). A fines de los años 80 (ochenta), la libreta de maternidad dedicada al control del embarazo también incluye los escritos relacionados con las prácticas de memoria en la familia.

\section{Los álbumes de nacimiento}

A principios del siglo XX, estas libretas usadas en el sector de la cura, originan la estructura y la organización de los primeros álbumes de nacimiento difundidos en el sector de la edición.

En el origen, estos álbumes o diarios de nacimiento se componían de cortos textos informativos sobre el crecimiento del chiquillo. Organizados cronólogica y temáticamente, iban con textos que completar que aparecen en la actualidad en un lugar 
preferente al lado de las ilustraciones y de los espacios reservados para las fotografías. Estas huellas, destinadas a mentar los destacados hechos de su existencia, sobretodo tienden a testimoniar las primeras veces de la primera infancia (Fine, Labro y Lorquin, 1993).

Provocó un fuerte auge de la oferta de álbumes y diarios de nacimiento el desarrollo de los bienes de consumo para la infancia (Cook, 2004) en todos los campos y especialmente en el de la edición. Así desde hace dos decenios por cierto, proponen los editores libros ilustrados en soporte de papel, pero también verdaderos cofrecillos encartonados donde colocar el libro y pequeños cajones para guardar los tesoros de la primera infancia: pulsera de identificación, mechón de cabellos, dientes de leche, primera ropa o par de zapatos, primeros dibujos... Estas huellas emblemáticas dan lugar a prácticas de colecta y de consevación parecidas a las de un coleccionista, que tienden a trasmitir su historia al niño.

Paralelamente al aumento de la oferta editorial, se desarrollaron las prácticas de las familias. En ellas caben prácticas de escritos, muchas veces hechos por las madres más implicadas en las cosas domésticas (Albert, 1993) que suelen escribir cuando el nacimiento y la primera infancia (Fine, 2000). Estas prácticas de escribir usuales estudiadas en los trabajos de antropología y de historia del escrito (Goody, 1979; Chartier, 2001), se juntan a la colecta, la clasificación y al archivo de huellas y llevan a la gente a comportamientos de apropiación de situaciones e influyen en los modos de percepción y de relación al mundo, se enfocan como instrumentos de pensamientos (Lahire, 1993 a y b). En estas operaciones caben actividades simbólicas y lingüísticas que pretenden fijar la historia individual y familar por el escrito y la imagen, a menudo llamando la atención en los «trozos escogidos». Sostienen la actividad de rememoración en el seno de la familia integrando al niño que suele ser el destinatario, el lector invitado (Francis, 2001, 2006, 2012) y que también puede ser coautor a varios niveles. Estas huellas materiales del nacimiento y la primera infancia, así como las prácticas que van asociadas, participan del movimiento que acompaña, al mismo tiempo que testimonia la figura del padre biógrafo y el proceso biográfico en el seno de la familia. 


\section{Muestra, metodología, objetivo del estudio}

Aquí proponemos el análisis secundario de un cuerpo recogido en varios estudios cualitativos realizados entre Diciembre de 2008 y Junio de 2013 en cuanto a los usos de los cuadernos, libretas y libros de vida, por las profesionales de la primera infancia de las guarderías infantiles y de las escuelas de párvulos (Francis, 2001, 2006, 2013 a y b). Se trata de puericultoras, educadoras, auxiliares maternas y maestras que utilizan cuadernos de vida bajo formatos de papel o electrónicos. El cuerpo encierra varios tipos de datos: el estudio de los cuadernos y libretas de vida, unas observaciones realizadas en las escuelas y las guarderías infantiles, entrevistas con 16 maestras de escuela de párvulos, de 3 profesionales de guarderías infantiles y de 12 auxiliares maternas. Entre estos estudios, dos (Francis, 2013 a y b) también tienen una parte ciberetnográfica con la exploración en la web de los contenidos de los cuadernos de vida electrónicos, así como los intercambios entre los contribuidores de los blogs, entre los cuales están los padres. Por fin, un estudio (Francis y Chapon, 2013) concirnió a un grupo de auxiliares familiares (11 mujeres y de un hombre de edad de 45 a 65 años que vivían todos ellos en Marsella) que acogen a niños colocados por un servicio Infancia-familia. Aquí encierra el cuerpo los álbumes de vida realizados en las instituciones, a veces durante varios años, transmitidos con la autorización de los niños, colocados por el ASE. El estudio de estos documentos ha sido completado por conversaciones mantenidas en el marco de una investigaciónación (Chapon, 2014).

Este amplio cuerpo fue sometido a un análisis de contenido temático, de tipo papel-lápiz.

El objetivo del estudio es proponer un panorama de las prácticas de las profesionales en el campo de las escrituras biográficas, en el período de la primera infancia y proponer un enfoque comparado entre las prácticas de las profesionales. 


\section{Relatos y pizcas de relatos de vida y sobre la vida de los chiquillos Cuadernos de vida y cuadernos viajeros en la escuela de párvulos}

En las clases de la escuela de párvulos, remonta a los años 80 (ochenta) la presencia de textos impresos o manuscritos archivados que tiende a testimoniar la vida del niño y las del grupo-clase. Reunidos en un cuaderno, a menudo llamado cuaderno de vida, estos relatos cortos, compuestos de escritos y de estampas, testimonian la vida del niño en la escuela y, a veces, en su familia. Mientras que el cuaderno de vida es un objeto individual y personalizado, más bien se refiere el libro de vida al grupo, sus proyectos, sus actividades, como lo demuestra el segundo texto que aparece al lado de una fotografía: « el Lunes, vimos un espectáculo de marionetas. Era la historia de un vendedor de globos y de una jirafa «.

Los cuadernos y los libros de vida deben ponerse en el contexto de la herencia de la Educación Nueva y de las pedagogías activas, las de los pedagogos Decroly y Ferrière, en particular (Houssaye, 2002). Como consecuencia de estos pedagogos, Célestin Freinet elaboró las teorías educativas vinculadas al cuaderno de vida, basadas en la necesidad de expresión del chiquillo. Subrayo la importancia de la producción de relatos de vida para, por una parte asociar a los padres con la experiencia vivida del joven niño y favorecer la comunicación entre el niño, la familia y la escuela; y, por otra parte, para permitir el proceso de aculturación al escrito articulando estrechamente pedagogía de lo oral, de lo escrito y de la lectura.

Los cuadernos de vida suelen estar en la escuela de párvulos desde los años 90 (noventa), período en el que el legislador puso énfasis en la importancia de la comunicación con las familias, y en el papel de la escuela de párvulos en el desarrollo del lenguaje oral y escrito. Las formas y los usos de los cuadernos y los libros de vida son muy variados. Los dispositivos en que la escuela los integra determina igual que influyen en la comunicación por las prácticas lingüísticas infantiles - referencias a la experiencia escolar a partir de los documentos archivados y de los relatos que van con ellas, transmisiones de informaciones vinculadas a los proyectos que exponen - los intercambios escuela-familia especialmente por las prácticas familiares de producción de los textos. 
Por lo menos concierne el dispositivo a dos niveles entre los cuales, primero, los modos de producción de los textos en el espacio escolar. En el espacio escolar, los niños resultan más o menos implicados en los modos de producción de los textos, en el proceso de producción escrita, por el dictado al adulto por ejemplo, y cuando van asociados estrechamente con la realización y con archivo de los textos - composición de los mensajes gracias a la imprenta o el ordenador, ilustración de estos mensajes. Cuanto más son los niños coproductores de estos relatos de vida, más son activos mensajeros entre sí, pero también entre la escuela y la familia.

A segundo nivel, concierne el dispositivo de la puesta en circulación de los libros y cuadernos de vida, en el seno de la clase, de la escuela y entre la escuela y la familia. Esta puesta en circulación de los cuadernos y libros de vida, según su regularidad y su frecuencia dinamiza más o menos el proceso de comunicación. También es importante la flexibilidad del dispositivo.

Ciertos dispositivos, por su forma y la interpretación que se hace de ellos, pueden revelarse más o menos rígidos y ser percibidos como formas de marco por las familias. Pueden originar tensiones en las relaciones maestras-padres y revelarse contraproducentes. Sin embargo en numerosos casos, estos cuadernos de vida a iniciativa de la escuela son recuperados por las familias, que en ellos ven una forma de prolongamiento de las prácticas de escritura de nacimiento, propicias a la puesta en memoria de los momentos emblemáticos y de los rituales de la tierna infancia.

Desde principios de los años 2000, al comprobar una adhesión débil de ciertos padres, particularmente en los medios populares, unos profesores privilegiaron otras formas, con una fuerte dimensión ludo-afectiva. Asociado con una mascota - animal o muñeco de felpa - que pertenece al universo escolar del niño, el cuaderno viaja entre la escuela y las familias, de aquí el nombre de cuaderno viajero que a veces se le da. Conciernen los relatos de vida, a los niños en la escuela y en sus familias. Pretende el dispositivo promover su producción - textos y grabados - en el seno de las familias, a partir de las aventuras de esta mascota en los medios de vida de los niños. El préstamo de una máquina de fotos numérica tiende a fomentar la producción de relatos compuestos de escritos y de fotografías realizados en la familia o en la escuela. Impresas en la escuela 
o en casa, éstas son archivadas en el cuaderno viajero al lado de los relatos producidos en la familia.

Este texto, escrito de la mano de una madre, testimonia las aventuras de la mascota Tibou, en casa de un niño: «el Miércoles, me fui con Tibou a casa de mi abuela, también lo encontró muy majo. Estoy muy contento de tener a Tibou en mi casa, quiero que vuelva muy rápidamente porque lo quiero mucho». El relato es coproducido con Yann, de 4 años, y la fotografía que lo muestra sobre el asiento de un coche con el muñeco de peluche, va acompañada de la frase: «Tibou y yo en el coche con mamá».

\section{Las libretas de vida de las guarderías infantiles y de las auxiliares maternas}

También las auxiliares maternas realizan cuadernos de vida para los niños (de 2 meses a 3 años) a quienes acogen. Cuando tienen un formato papel, estos cuadernos de vida suelen tener una forma individual. Los relatos de vida generalmente escritos en nombre del niño se fijan en la vida diaria del niño, en sus progresos y las primeras veces, en casa de las auxiliares maternas: «hoy, dí mis primeros pasos en casa de la tía» o en su presencia, "fui al sitio de las Auxiliares Maternas y Martine nos leyó una historia ».

En las guarderías infantiles el cuaderno de transmisiones a menudo es utilizado. Las profesionales, sobre todo cuando se relevan cerca del niño, apuntan diariamente informaciones sucintas en cuanto al sueño, las comidas, los cuidados. El objetivo de este soporte práctico, es el intercambio entre profesionales y dar a los padres informaciones sobre el día de su nene. Es diferente de la libreta de vida, en que son recogidas huellas de gran valor de afectividad y memoria. Los escritos que la componen se refieren a los hechos notables de la vida del niño joven. Estos escritos cortos de tipo biográfico, que cada vez más a menudo van acompañados de fotografías, dan una imagen sensible de la vida social del niño joven, de sus actividades, sus primeras amistades. 


\section{Los blogs, cuadernos de vida bajo formato electrónico}

En la escuela de párvulos, también los cuadernos de vida son propuestos bajo formato electrónico como lo muestran los estudios sobre los blogs hechos por las maestras de escuela de párvulos. Si ciertos blogs están a uso estrictamente profesional o revisten formas híbridas (Francis, 2013a), ya que el cuaderno de vida de la clase es completado por rúbricas profesionales, que por ejemplo, integran la presentación de secuencias, de recursos pedagógicos o de lazos hacia los programas oficiales del ministerio de educación, otros blogs se refieren a la vida de la clase.

Entonces podemos hablar de cuadernos colectivos de vida bajo formato electrónico. Sin embargo, los diferencian destacadas características y podemos distinguir tres categorías:

- Los que se fijan en la vida de la escuela. Insistiendo en la presentación de proyectos emblemáticos, también tratan de acontecimientos excepcionales de la vida de clase, - Los que se centran en la vida de clase insistiendo en la presentación de las actividades de los niños, y, - Los que integran además de elementos anteriormente citados, las relaciones entre los espacios educativos, haciendo referencia a los intercambios entre la escuela, la familia y las profesionales de la tierna infancia, por ejemplo, las auxiliares maternas que se encargan de acoger a los chiquillos antes de su ingreso en la escuela de párvulos.

El fin de estos cuadernos colectivos de vida bajo formato electrónico, es constituir una memoria de la escuela, de la clase y contribuir a los lazos con la familia. Los comentarios de los padres, los blogueros contribuidores, revelan los usos de estos blogs en el seno de las familias: consulta del blog con el niño y sus hermanos, conversaciones familiares sobre los acontecimientos presentados, lectura de textos, visualización de las imágenes fijas y animadas, escucha de canciones puestas on-line, lectura de las historias contadas en clase, realización de recetas de cocina confeccionadas en la escuela... Estos cuadernos de vida bajo forma de blogs, con su flexibilidad de utilización, son consultados por los padres, y también por los miembros de la familia ampliada, especialmente los abuelos. 
A veces, también tienen los cuadernos de vida realizados por las auxiliares maternas, un formato electrónico. Localizados en la web, los relatos se refieren a las actividades del grupo de niños acogidos por la auxiliar materna, a veces los propios niños de la auxiliar materna. Las formas de textos resultan diversificadas con relatos, compuestos de textos y de grabados fijos o animados, a menudo coproducidos por los adultos y los niños. Consta la comunidad de los lectores, de los padres y del círculo familiar ampliado. Más para los blogs abiertos por las maestras, los padres interactúan con las profesionales y entre sí. Componen la comunidad de los lectores-contribuidores junto con otros miembros de la familia, los abuelos o también los tíos y las tías, los padrinos y las madrinas. Cuando viven lejos de los chiquillos, estos cuadernos electrónicos de vida, son la ocasión de descubrir su contexto de vida, sus actividades y sus progresos.

En la comunidad de los blogueros-lectores-contribuidores, también consta de los niños que así mantienen el contacto con su antigua ama de cría o maestra. Según su edad, los niños envían mensajes y fotografias, e interactúan entre sí, a veces a través de los padres.

\section{Los álbumes de vida y « cajas de tesoro « de las auxiliares familiares}

Las profesionales de las instituciones de nacimiento, así como las familias de acogida, utilizan la libreta de vida del niño con el fin de relatar el nacimiento y la tierna infancia, cuando el nacimiento o la primera infancia intervienen en un contexto de discontinuidades (Francis y Chapon, 2013). Entonces se trata de sostener la construcción identitaria del chiquillo y de su futura familia (Michel, Perel y Wrobel, 2002).

Cuando los niños son acogidos por auxiliares familiares, es realizado un trabajo de archivo de los primeros momentos de encuentro y de vida bajo la forma de fotografías y de escritos que presentan el desarrollo de la vida del niño y sus principales acontecimientos. Ciertas auxiliares maternas, dan gran importancia a la fotografía y entonces los clisés van acompañados de numerosos comentarios. Otros conceden una gran importancia al escrito, como es el caso de aquella auxiliar familiar: «cuando llegan los niños a mi casa, tomo un cuadernillo y de cuando en cuando, cuento un poco lo que pasa en 
su vida, los acontecimientos, así cuando se vayan todos tendrán un cuaderno con anécdotas, una parte de su vida escrita». En un caso como en el otro, los momentos considerados como marcadores en la historia del niño colocado - los primeros contactos con el niño, su llegada a la familia - quedan registrados en estos álbumes de vida.

Según el período de la infancia y la duración de la colocación, el escrito se estructura de otro modo, traduciendo y/o reflejando diferentes enfoques de la temporalidad. Cuando crece el niño, la práctica de asociar lo visual con la descripción escrita en estos álbumes de vida va escaseando.

Una diversidad de documentos componen las huellas de vida recogidas y archivadas por las auxiliares familiares. Además de los álbumes de vida, hay los cuadernos de contacto realizados por la auxiliar familiar, a menudo para otros adultos, los educadores o el juez de menores. Ahí se apuntan las notas tomadas durante su colocación, a propósito de las visitas paternas, o todavía las cartas recibidas de los miembros de la familia. También las auxiliares familiares tienen una voluntad de conservar los escritos de los padres, aún cuando el niño no lo desea. Su objetivo es que puedan acceder a ello un día cuando sea mayor o cuando lo desee como lo precisa una auxiliar familiar: " tiró las cartas de su madre, entonces las recogí y las guardé en una caja para él más tarde» Marie-Noelle, 58 años

Ciertas auxiliares familiares producen las fotografías de los niños en varios ejemplares para dárselas a los padres, otras realizan dos álbumes de vida, con el fin de que el niño comunique acerca de los textos y fotografías. Cuando los niños son pequeños, los auxiliares familiares en esto ven un medio de ayudar al niño para que construya su historia entre sus diferentes lugares de vida.

A los álbumes de vida se añaden las huellas producidas por el niño mismo, y conservadas como otros tantos «tesoros». Se trata de los dibujos, los textos escritos para la familia de acogida o para sus padres biológicos entre los cuales cartas, $¥$ postales y poemas. Raboua, de origen de Mayotte, colocado en su familia de acogida desde la edad de dos años, con su hermanito escribe muchos, poemas y cartas. También dibuja. Algunos de sus poemas están guardados en su caja de recuerdos, a veces después de quedar fijadas en el comedor desde hace años, como este texto escrito en 2010 y que, en 2013, 
sigue en la pared del salón: "Tía, eres el agua que riega las flores, el sol que hace que se abran, el mar para hacer navegar los barcos, el rotulador para dibujar, el amor que ahí está entre toda la familia igual que papá».

También los auxiliares familiares conservan en estas cajas de tesoro las «cositas» que acompasan un día excepcional. Estos objetos de papel que ilustran una salida excepcional, la pequeña ropa que llevaba el niño cuando llegó de la guardería infantil, su mantita, sus chupetes... son otros tantos objetos fetiches de su historia. A menudo se le entrega al niño la «caja de recuerdos» como lo explica Dak: «conservé todo lo que tenía cuando llegó, la ropa que llevaba. Lo puse todo en una caja. Escribí su historia para ella, luego se lo devolví».

\section{Relación con la escritura, la imagen, las tecnologías numéricas}

Entre los profesionales, las auxiliares familiares muchas veces mentan dificultades en escribir. Algunas subrayan las dificultades de aprendizaje de la lengua escrita, particularmente las auxiliares familiares cuyo primer idioma no es el francés. A diferencia de los escritos de las auxiliares maternas, profesionales de las guarderías infantiles y maestras, las producciones son el tema principal de lo importante en la memoria, para los niños colocados. Sus prácticas de colecta, de archivo y de escritura pueden constituir las únicas huellas de la memoria de la primera infancia. Para todas las profesionales es la fotografía un facilitador; acompaña y sostiene lo escrito, incluso para las auxiliares familiares cuya experiencia profesional anterior -de educadora, de secretaria- les permitió adquirir una soltura frente al escrito.

Las auxiliares maternas suelen tener un nivel de formación casi igual al de las auxiliares familiares. No mentan dificultades en cuanto a lo escrito, y podemos hacer la hipótesis que lo que está en juego - la memoria, la afectividad, las instituciones - con las que se relaciona son menores, en lo que toca al niño, su familia biológica, pero también las relaciones con las profesionales encargadas de las progresiones del niño y su propia carrera. Para las auxiliares maternas, el recurso de lo escrito testimonia la voluntad de profesionalizar su acción, un escrito producido se vuelve disponible gracias a las 
tecnologías numéricas. En efecto, los cuadernos de vida, en acceso libre o reservado para las personas autorizadas, la mayoría de las veces tienen un formato electrónico. Si tienen como objetivo conservar las huellas de los tiempos importantes de la vida de los niños a quienes acogen y ofrecerles a los padres una vista sobre las modalidades de acogida y las actividades del chiquillo, estos relatos tienen por objeto crear lazos entre los espacios de vida de los niños y entre los adultos que los rodean.

Son estos escritos unas indicaciones biográficas cada vez más trabajadas por la plaza de las imágenes, fijas y animadas, y tecnologías numéricas. La relación con lo escrito se encuentra modificada por estas tecnologías que, como instrumentos socio-técnicos, ofrecen un marco organizador para la producción de los escritos, su difusión, su socialización. Por otro lado, que se trate del soporte de papel o del soporte numérico, las prácticas de las profesionales, insertadas en dispositivos que crean sentido, también están relacionadas con las prácticas infantiles en materia de consulta de los cuadernos y libretas de vida, de producción de los textos y de los usos de los instrumentos numéricos.

Los resultados de este estudio ofrecen una visión de conjunto de las prácticas biográficas de las profesionales y de los sentidos que encierran. Cuando el nacimiento, la primera infancia y la niñez se teje una trama de narraciones donde objetos, «saturados de significados implícitos» (Kaufmann, 1997, p. 113) contribuyen a la producción de relatos sobre el chiquillo, sobre su historia individual o sobre su historia en y por el grupo, el de la familia de acogida, de la guardería infantil, de la escuela de párvulos. Así, estos cuadernos y libretas de vida testimonian la perspectiva biográfica (Delory-Momberger, 2005) y los espacios de relación con sí mismo y con otros, profesionales, padres, el niño mismo coproductor de estas huellas que encierra. Estos relatos en el límite de los escritos «del yo» y «para el otro» (Lejeune y Bogaert, 2006) son entre litteracy y memoracy, ya que también se encuentran ahí transformados «la relación y la función de la memoria, de la huella y del archivo» (Gardey, 2008). Esta producción de escritos biográficos llevados por objetos e imágenes debe ser contemplada en relación con los datos centrales de la 
modernidad que son la reflexividad (Giddens, 1994) y el proceso de individualización (Martuccelli y de Singly, 2009) que tienen cada uno un papel motor en la producción de los relatos de sí.

\section{Referencias}

ALBERT, Jean-Pierre. «Écritures domestiques ». In: Fabre Daniel (dir.). Écritures ordinaires. Paris: POL, 1993, p.37-94.

BERTAUX-WIAME, Isabelle \& MUXEL, Anne. Transmissions familiales: territoires imaginaires, échanges symboliques et inscription sociale. In: De SINGLY, François; MARTIN, Claude; MUXEL, Anne. \& al. (Dir.) La Famille en questions l'Etat de la recherche. Paris: Syros, 1996, p. 187-210.

CATARSI, Elisabeta. «Educazione familiare e autobiografi e genitoriali». Rivista Italiana di Educazione Familiare, 1, 2008, pp. 5-18.

CAZALÉ BÉRARD, Christian \& KLAPISCH-ZUBER, Christiane. «Mémoire de soi et des autres dans les livres de famille italiens». Annales. Histoire, Sciences Sociales, 2004/4, p. 805-826.

COOK, Daniel Thomas. The Commodifi cation of Childhood, The Children's Clothing Industry and the Rise of the Child Consumer. Durham: Duke University Press, 2004.

CHAPON, Nathalie. La parentalité d'accueil et relations affectives. Aix-en-Provence, PUP, 2014. CHARTIER, Roger. "Culture écrite et littérature à l'âge moderne». Annales, $n^{\circ} 4-5$, p.783-802, 2001. 
CICCHETTI, Angelo et MORDENTI, Raul. «La scrittura dei libri di famiglia» In: Letteratura italiana, diretta da ANETTA, Asor Rosa, vol. III, Le forme del testo, t. II, La prosa, Torino: Einaudi, 1984, p. 1117-1159.

DELIEUVIN, Marie-Christine. Marc-Antoine Jullien, de Paris, 1775-1848. Théoriser et organiser l'éducation. Paris: L'Harmattan, 2003.

DELORY-MOMBERGER, Christine. La condition biographique. Essai sur le récit de soi dans la modernité avancée, Paris, Téraèdre, 2010.

DESEILLIGNY, Oriane. «La mémoire appareillée: dispositifs numériques et écriture de soi ». Journal for Communication Studies, vol. 5, no. 2(10), 2012.

DESEILLIGNY, Oriane. «Du journal intime au blog: quelles métamorphoses du texte?». Communication \& Langages, 155, p. 45-62, 2008. FABRE, Daniel (Dir). Écritures ordinaires. Paris: Editions POL-Centre Georges Pompidou, 1993.

FINE, Agnès. «Écritures féminines et rites de passage». Communications, 70, p. 121-142, 2000.

FINE, Agnès; LABRO, Stéphanie \& LORQUIN, Claire. Lettres de naissance. In: Fabre D., Ecritures ordinaires. Paris, Editions POL-Centre Georges Pompidou, 1993, pp.116-147.

FOISIL, Michel. «L'écriture du for privé» In : Philippe Ariès \& DUBY, Georges. Histoire de la vie privée. Tome 3. Paris: Seuil, 1999, pp. 319-357.

FRANCIS, Véronique. "Becoming a parent: what parental writings teach us". In: La Sala G.B., FAGANDINI, Philippe, Monti F. \& Blickstein I. (Eds), Coming into the World: A Dialogue between Medical and Human Science, Berlin/New-York, De Gruyter, 2006, pp.6584.

FRANCIS, Véronique. «Pratiques d'écriture et processus de parentalité ». In: Actes du colloque Le biographique, la réfl exivité et les temporalités, Tours, 25-27 juin, 2007, pp.62-65.

FRANCIS, Véronique. «Devenir mère: le blog comme trace du compte à rebours». In: XIIlème Congrès International de l'Association Internationale Francophone de Recherche en Education Familiale, Florence, 17-19 nov, 2010, http://www.aifref2010.org/FR/home.html.

FRANCIS, Véronique. Pais Biógrafos. Escritas familiares e diários de nascimento. Revista Eletrônica de Educação. Vol. 5 N²/2011, pp. 214-235.

http://reveduc.ufscar.br/index.php/reveduc/article/view/279

FRANCIS, Véronique. «Les journaux et albums de naissance. Pratiques familiales, fi gures et projets du parent biographe ». Rivista Italiana di Educazione Familiare, n¹, 2011b.

FRANCIS, Véronique. «Oggetti della nascita e processo biografi co» In: CADEI, Livia \& DOMENICO, Simeone (dir.), L'attesa. un tempo per nascere genitori. Roma: Unicopli, 2013a, pp. 33-64 (Traduction: Naître au monde, naître au récit. Objets de naissance et processus biographique. In Devenir parents. Transformations et processus formatifs). 
FRANCIS, Véronique. «Blogs et cahiers de vie numériques à l'école maternelle: usages et effets sur les pratiques enseignantes et familiales» Colloque international éTIC, Les TICE à l'école primaire. Limoges, 3-4 octobre, 2013b.

FRANCIS, Véronique. \& CADEl, Livia. « Les blogs des parents: des pratiques d'écriture parentale comme forme de soutien de la parentalité. » In: SCHNEIDER, Benjamin \& MIETKIEWICZ, Marie-Christine. (dir.). Les enfants dans les livres. Représentations, savoirs, normes. Toulouse: Eres, 2013, pp. 150-167.

FRANCIS, Véronique. \& CHAPON, Nathalie. «Approches biographiques en protection de l'enfance: Pratiques, effets sur les parents, les enfants, les professionnels». In: Congrès international de l'AREF, Actualité, recherche, éducation et formation, 27-30 août, Montpellier, 2013 http://www.aref2013.univ-montp2.fr/cod6/?q=content/educationfamiliale-technologies-delinformation-et-de-la-communication-processus Garat, A.M. Photos de familles. Paris, Actes Sud, 2011.

GIDDENS, Anthony. Les conséquences de la modernité. Paris, L'Harmattan, 1994. Goldin, Daniel. " La paternité et les livres, réfl exion sur l'hospitalité de la lecture». Les Cahiers d'ACCES, 2003.

GOODY, Jack. La raison graphique. La domestication de la pensée sauvage. Paris, Editions de Minuit, 1979. Halbwachs, M. Les cadres sociaux de la mémoire. Paris: La Haye- Mouton, 1925.

HESS, Rémi. La pratique du journal: I'enquête au quotidien. Paris, Anthropos, 1998. HOUSSAYE, Jean. Quinze pédagogues. Leur infl uence aujourd'hui, Paris: Bordas, 2000. ILLIADE, Kareen. Marc-Antoine Jullien, Essai sur l'emploi du temps (1808). Paris, Anthropos, 2006.

KAUFMANN, Jean-Claude. «Le monde social des objets». Sociétés Contemporaines, 27, 1997.

LAHIRE, Bernard. La Raison des plus faibles. Rapport au travail, écritures domestiques et lectures en milieux populaires. Lyon: PUL, 1993.

LAHIRE, Bernard. «La transmission familiale de l'ordre inégal des choses». Regards croisés sur l'économie, $1 \mathrm{n}^{\circ}$ 7, p. 203210, 2010.

LEJEUNE, Philippe. Le Pacte autobiographique. Seuil, 1975, coll. « Points», nouv. Ed, 1996.

LEJEUNE, Philippe. Signes de vie, Le Pacte autobiographique 2. Seuil, 2005.

LEJEUNE, Philippe. \& BOGAERT, Claude. Le Journal intime. Histoire et anthologie. Paris, Textuel, 2006. Lejeune, P. «Le récit de soi, c'est lui ». Le monde des livres, 2 mai, 2013.

LE WITA, Béatrix. «Mémoire, l'avenir du présent ». Terrains, nº, p. 15-26, 1985. MAC KENZIE, Daniel. La Bibliographie et la sociologie des textes. Paris: Cercle de la Librairie, 1991.

MARTIN-FURGIER, A. « Les Rites de la vie privée bourgeoise ». In: ARIÈS, Philippe. et DUBY, Georges. (Dir) Histoire de la vie privée. Tome 4, De la Révolution à la grande guerre. Paris: Seuil., 1987, pp. 193-262. 
MICHEL, France, PEREL, Monique, WROBEL, Georges. «Premières traces, vers un carnet de vie». In ROBINEAU, Chistian, Filiations à l'épreuve, Toulouse: Eres, 2002.

MARTUCCELLI, Danilo, DE SINGLY, François. Les sociologies de l'individu. Paris: Colin, 2009.

MASNY, Diana; DUFRESNE, Thérèse. « Apprendre à lire au 21e siècle ». In : DIONNE, AnneMarie et BERGER, Josée Marie (dir.) Les littératies, perspectives linguistique, familiale et culturelle, Ottawa: Presses de l'Université d'Ottawa, 2007.

NEUBURGER, Robert. Les rituels familiaux. Paris: Payot, 2006.

ROLLET-ECHALIER, Catherine. Petite histoire du carnet de santé ou l'objectif de la santé pour tous La Politique à l'égard de la petite enfance sous la Illème République. Paris:

INED-PUF, 1990.

SIMONET-TENANT, Françoise. Le Journal intime, Genre littéraire et écriture ordinaire. Paris: Téraèdre, 2004.

SITÀ, Chiara. «Dentro la ricerca. Noi e le famiglie» In: VANNA, lori \& LUIGINA, Mortari. Per una citta' solidale. Le risorse informali nel lavoro sociale. Milano, Unicopli, 2005, p. 139162.

Universidade do Estado de Santa Catarina - UDESC Programa de Pós-Graduação em Educação - PPGE 